03.4

\title{
Применение вспомогательных топлив для управления сверхзвуковыми потоками реагирующих топливно-воздушных смесей в канале камеры сгорания
}

\author{
(C) С.В. Колосенок ${ }^{1,2}$, А.Л. Куранов ${ }^{1}$, А.А. Саваровский ${ }^{1, \uparrow}$, П.В. Булат ${ }^{2}$, А.А. Галаджун ${ }^{2}$, \\ А.А. Левихин ${ }^{2}$, А.Б. Никитенко ${ }^{2}$ \\ ${ }^{1}$ ОАО „Научно-исследовательское предприятие гиперзвуковых систем“, Санкт-Петербург, Россия \\ ${ }^{2}$ Балтийский государственный технический университет „Военмех“ им. Д.Ф. Устинова, Санкт-Петербург, Россия \\ ฯE-mail: mail@hypersonics.ru
}

Поступило в Редакцию 11 марта 2021 г.

В окончательной редакции 22 июня 2021 r.

Принято к публикации 22 июня 2021 г.

\begin{abstract}
Для реализации устойчивого сверхзвукового горения углеводородных топлив помимо газодинамических способов пригодны также химические. В ходе исследований экспериментальной модели уделено внимание кремнийорганической жидкости, поскольку элементоорганические соединения известны своей высокой реакционной способностью. Скорость распространения ламинарного пламени в смеси этой жидкости с воздухом составила $0.72-0.8 \mathrm{~m} / \mathrm{s}$. Это выше, чем у этилена, успешно использовавшегося в тестах сверхзвукового горения. Протестированное соединение может рассматриваться в качестве дополнительного топлива для управления сверхзвуковыми реагирующими потоками в камерах сгорания прямоточных двигателей.
\end{abstract}

Ключевые слова: сверхзвуковое горение, вспомогательные топлива, скорость ламинарного пламени, эффективность сгорания.

DOI: 10.21883/PJTF.2021.19.51507.18764

Для обеспечения высокой эффективности применения углеводородного топлива в прямоточных двигателях при числе Маха $\mathrm{M}=2-3, T=800-1000 \mathrm{~K}$ и $p=0.5-1 \mathrm{~atm}$ на входе в камеру сгорания (КС) [1] требуется выполнение условия $\mathrm{M} \geq 1$ для части канала КС, занятой пламенем. В этой области время пребывания потока составляет единицы миллисекунд. Например, согласно [2], времени задержки воспламенения керосина $2 \mathrm{~ms}$ соответствуют температуры порядка $1400 \mathrm{~K}$, а продуктов крекинга керосина - $1550 \mathrm{~K}$. Таким образом, для реализации горения в канале необходимо повышение температуры, достигаемое в том числе за счет механизма подмешивания продуктов сгорания (ПС) в турбулентных вихрях, что проиллюстрировано расчетами поля величин времени протекания химических реакций в диффузных сверхзвуковых пламенах [3]. Поэтому реакционная способность топлив при высоких начальных температурах является их важной характеристикой. Регулировка числа Маха ниже точки впрыска топлива осуществляется путем изменения коэффициента избытка окислителя $\alpha$ [4], но стабилизация требуемой скорости пламени подобным способом затруднена. Так, для КС с двумя пилонами было показано, что при регулировке расхода топлива через инжектор верхнего (по потоку) пилона возникают гистерезисные явления около $\mathrm{M}=1$ [5].

Применение топлив, которые при сгорании высвобождают энергию значительно быстрее керосина, позволило бы на сравнительно меньшей длине участка КС менять профиль давления в канале (подробнее см. [6]). К таким топливам относятся водород, этилен, моносилан, применявшиеся как в наземных, так и в полетных экспериментах, но их размещение на борту летательных аппаратов сопряжено со значительными трудностями. Известные жидкости, успешно применявшиеся в тестах высокоскоростного горения, сильно токсичны либо пирофорны. По этой причине применение дополнительных топлив при исследованиях процессов в КС гиперзвуковых прямоточных воздушно-реактивных двигателей в последнее время ограничивалось газами. Цель настоящей работы - предложить экспресс-метод отбора возможных жидких дополнительных топлив.

Помимо экспериментов с моделями КС и численных расчетов кинетики реакций в сверхзвуковых потоках активность топлив можно оценивать также полуэмпирическими методами. Существует, например, монотонная зависимость между ламинарной скоростью распространения пламени в топливно-воздушных смесях (ТВС) водорода, синтез-газа [7], этилена и задержкой воспламенения этих топлив в подогретом сверхзвуковом потоке [8]. Структуру фронта ламинарных предсмешанных пламен можно представить состоящей из зоны прогрева, в которой реагенты подогреваются до высоких температур, и смежной с ней зоны реакции, в которой происходит значительное изменение состава смеси. Скорость таких пламен определяется температуропроводностью смесей и временем протекания реакций в них (порядка $1 \mathrm{~ms}$ при 1 bar). Таким образом, скорость ламинарного пламени может указывать на кинетику реакций в ТВС, в том числе при высоких начальных температурах. Поэтому результаты исследования ламинарных пламен могут 
Основные продукты сгорания ТМДС (в мольных долях)

\begin{tabular}{c|c|c|c|c|c|c|c|c}
\hline$\alpha$ & $p$, atm & $T, \mathrm{~K}$ & $\mathrm{~N}_{2}, \%$ & $\mathrm{H}_{2} \mathrm{O}, \%$ & $\mathrm{CO}_{2}, \%$ & $\mathrm{SiO}_{2}$ (liq.), \% & $\mathrm{CO}, \%$ & $\mathrm{H}_{2}, \%$ \\
\hline 1 & 1 & 2418 & 71 & 14 & 6.2 & 3.8 & 1.6 & 0.6 \\
0.85 & 1 & 2420 & 69 & 14 & 4.5 & 4.2 & 4.4 & 2.2
\end{tabular}

применяться для реализации систем со сверхзвуковым горением. Следует отметить, что в сверхзвуковых потоках существуют только турбулентные пламена — как предсмешанные, так и диффузные, т. е. ламинарное предсмешанное пламя является крайне упрощенной экспериментальной моделью и пригодно преимущественно для скрининга возможных вспомогательных топлив. В настоящее время основные способы измерения ламинарных скоростей сгорания ТВС осуществляются в сферических взрывах и с помощью горелок.

В качестве примера топлив с хорошей химической кинетикой можно взять кремнийорганические соединения. Некоторые из них в отличие от аналогов (алюмоорганика, бороорганика) относительно безопасны в обращении, при этом устойчивы к нагреву до $400^{\circ} \mathrm{C}[9]$ и являются жидкостями. Согласно тестам, проведенным в 50-х годах XX века, они сгорают быстрее керосина и нередко быстрее этилена [10]. В современной работе [11] была верифицирована скорость горения тетраметилсилана, соответствующая ранее измеренной $(0.6 \mathrm{~m} / \mathrm{s})$. Можно обратить внимание на 1, 1, 3, 3-тетраметилдисилоксан (ТМДС), используемый как восстановитель в органическом синтезе [12]. Его температура кипения $71^{\circ} \mathrm{C}$, плотность $0.76 \mathrm{~g} / \mathrm{cm}^{3}$. Термическая стабильность этого соединения ниже, чем у алкилзамещенных силанов, однако в состав продуктов его сухого пиролиза по доминирующему механизму входит 50\% диметилсилана [13], что позволяет ожидать сохранения химикокинетических свойств перегретого ТМДС. Нами была получена экспресс-оценка ламинарной скорости горения этого соединения методом фоторегистрации сферического взрыва ТВС. Реакция сгорания ТМДС

$$
\mathrm{C}_{4} \mathrm{H}_{14} \mathrm{Si}_{2} \mathrm{O}+9 \mathrm{O}_{2}=4 \mathrm{CO}_{2}+7 \mathrm{H}_{2} \mathrm{O}+2 \mathrm{SiO}_{2} \text {. }
$$

Двуокись кремния $\left(\mathrm{SiO}_{2}\right)$ встречается в природе и входит в состав промышленной продукции. Из-за высоких температур реакции в продуктах сгорания присутствует мелкокристаллическая фаза $\mathrm{SiO}_{2}$, концентрация которой в воздухе помещений должна жестко ограничиваться. Поэтому тестовый реактор (см. рисунок) работал на разгрузку через легкоразрушаемую диафрагму в замкнутую вспомогательную емкость, которую нужно промывать после каждого эксперимента. Возрастание давления в реакторе было ограничено, и исследования проводились в режиме „постоянного давления“. Диаметр смотрового окна в реакторе $140 \mathrm{~mm}$. В центре реактора находятся два острых электрода. Межэлектродное расстояние варьировалось от 1 до $3 \mathrm{~mm}$. Опыт запускался с помощью искрового генератора с энергией искры порядка

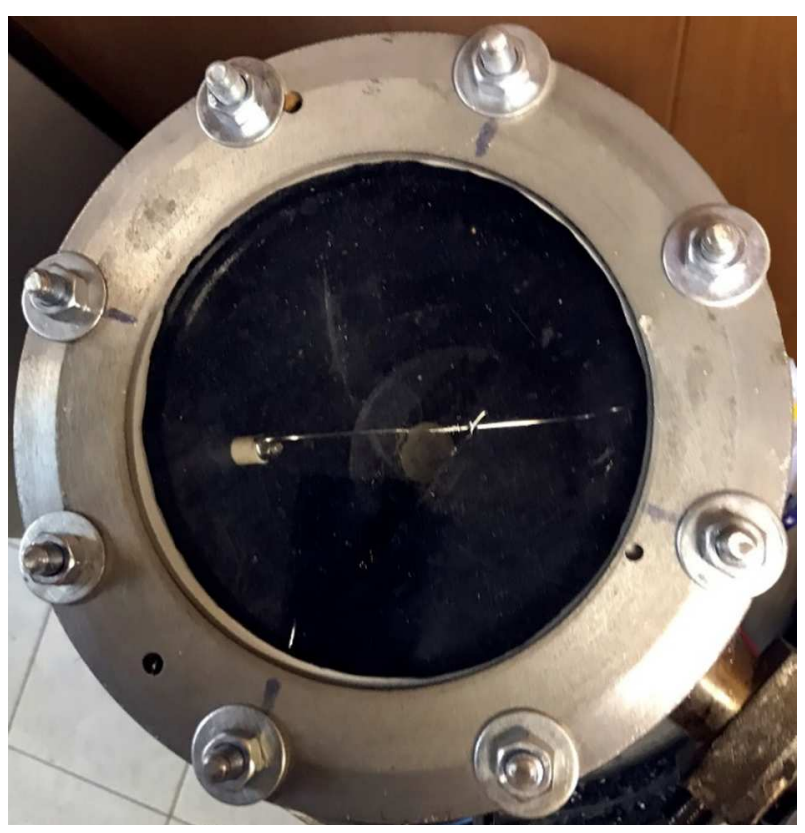

Реактор для исследования ТВС.

нескольких mJ. Объем реактора составлял $1.25 \mathrm{dm}^{3}$. С помощью гексано-воздушной смеси была получена оценка предельного радиуса неискаженного пламени $(\sim 2.5 \mathrm{~cm})$, при этом прирост давления $\Delta p$ не превысил $5 \%$. Измерения проводились камерой с максимальной частотой кадров $1200 \mathrm{~s}^{-1}$. Тесты осуществлялись при исходных температурах $T_{0}=280-290 \mathrm{~K}$.

Ламинарная скорость вычисляется по закону сохранения расхода среды через фронт пламени

$$
\begin{aligned}
u_{L} & =\left(\rho_{1} / \rho_{0}\right) d R / d t=\left(T_{0} V_{0} / T_{1} V_{1}\right) d R / d t \\
& =\left(T_{0} N_{0} / T_{1} N_{1}\right) d R / d t
\end{aligned}
$$

где $R$ - радиус пламени в момент времени $t, \rho_{0}-$ плотность ТВС, $\rho_{1}$ - плотность ПС, $V_{0}-$ удельный объем ТВС при нормальных условиях, $V_{1}-$ удельный объем ПС при нормальных условиях, далее из расчета сжигания $1 \mathrm{~mol}$ ТМДС: $N_{0}-$ количество компонентов TBC в mol, $N_{1}$ - количество компонентов ПС в mol, кроме конденсированной фазы, не занимающей объема. Коэффициент избытка окислителя $\alpha$ задавался около 0.85. Зарегистрированная скорость распространения пламени лежит в пределах $6.3-7 \mathrm{~m} / \mathrm{s}$ с учетом погрешности измерений. Для вычислений использовались кадры с $R \geq 5 \mathrm{~mm}$, а коррекция величин скорости с учетом 
кривизны фронта пламени не проводилась. Расчет с использованием программы TERMORAS показал, что $T$ пламени ТМДС не превышает $2420 \mathrm{~K}$. Для вычисления $N_{1}$ использовались результаты расчета состава ПС (см. таблицу), незначительно отличающиеся от пропорций, следующих из правой части уравнения (1). Оценки $u_{L}$ ТМДС по формуле (2) лежат в пределах $0.72-0.8 \mathrm{~m} / \mathrm{s}$, тогда как у этилена $u_{L}=0.7 \mathrm{~m} / \mathrm{s}$.

Таким образом, представляется реалистичным рассматривать вместо газообразных топлив жидкости для управления сверхзвуковыми реагирующими потоками, например, в трактах КС прямоточных воздушнореактивных двигателей. При выборе подобных соединений должны учитываться опасность в обращении и реакционная способность.

\section{Конфликт интересов}

Авторы заявляют, что у них нет конфликта интересов.

\section{Список литературы}

[1] M.K. Smart, AIAA J., 50 (3), 610 (2012). DOI: $10.2514 / 1 . J 051281$

[2] S. Xu, Q. Liao, Proc. Eng., 99, 338 (2015). DOI: 10.1016/j.proeng.2014.12.544

[3] M. Karaca, S. Zhao, I. Fedioun, N. Lardjane, Aerospace Sci. Technol., 89, 89 (2019). DOI: 10.1016/j.ast.2019.03.050

[4] X. Gao, X. Han, Q. Fu, in Sixth Int. Conf. on intelligent control and information processing (ICICIP) (Wuhan, China, 2015), p. 501.

[5] Z. Shaohua, X. Xu, Proc. of the Institution of Mechanical Engineers, Part G: J. Aerospace Eng., 232 (10), 1864 (2017). DOI: $10.1177 / 0954410017708213$

[6] А.Л. Куранов, С.В. Колосенок, А.Б. Никитенко, А.А. Саваровский, Формула полезной модели RU 192758 U1.

[7] W. Han, P. Dai, X. Gou, Z. Chen, Appl. Energy Comb. Sci., 1-4, 100008 (2020). DOI: 10.1016/j.jaecs.2020.100008

[8] P.K. Tretyakov, A.V. Tupikin, A.L. Kuranov, S.V. Kolosenok, A.A. Savarovskii, V.M. Abashev, Combust. Explos. Shock Waves, 56, 533 (2020). DOI: 10.1134/S0010508220050044

[9] G. Fritz, Z. Anorgan. Allg. Chem., 273 (3-5), 275 (1953). DOI: $10.1002 /$ zaac. 19532730320

[10] M. Gerstein, Symp. (Int.) Combust., 7 (1), 903 (1958).

[11] J. Chao, J. Lee, C. Bauwens, S. Dorofeev, J. Loss Prev. Process Ind., 36, 471 (2015). DOI: 10.1016/j.jlp.2014.11.019

[12] J. Pesti, G.L. Larson, Organ. Process Res. Dev., 20 (7), 1164 (2016). DOI: 10.1021/acs.oprd.6b00124

[13] M.J. Almond, R. Becerra, J.A. Bowes, J.P. Cannady, J.S. Ogden, N.A. Younge, R. Walsh, Phys. Chem. Chem. Phys., 11 (40), 9259 (2009). DOI: 10.1039/B910549B 